\title{
DENTES TEMPORÁRIOS: ASPECTOS HISTOLÓGICOS
}

\section{SINOPSE}

Foram estudados os caracteres histológicos diferenciais entre os dentes deríduos e os dentes permanentes, estabelecendo-se algum relacionamento elínico.

Frequentes perguntas sôbre as características histológicas dos dentes temporários e o convite para participar do simpósio da Primeira Semana de Odontopediatria e Ortodontia Preventiva de Pôrto Alegre levaram-nos à elaboração do presente trabalho.

Sem a pretensão de descer a grandes profundidades, procuraremos apresentar o que de mais significativo encontramos no exame dos preparados histológicos e da bibliografia visando dar uma idéia geral das principais características, estabelecendo comparação com os dentes permanentes. Iniciaremos com uma rápida incursão sôbre as diferenças macroscópicas e, em seguida, analisaremos os aspectos histológicos diferenciais.

\author{
Leopoldo Marques Louro \\ Professor Regente da Histologia e \\ Embriologia do Departamento 2.
}

\section{ASPECTO MACROSCóPICO}

Quanto ao volume - Os dentes temporários são de menor porte, aproximadamente $1 / 3$ a menos que os homólogos da dentição permanente.

Quanto à côr - Os dentes de leite são de coloração mais clara, esbranquiçados, enquanto os permanentes tendem ao amarelado.

A côr de todos os dentes parece depender muito mais da coloração da dentina que do esmalte. Através do esmalte vê-se a côr da dentina.

o relacionamento da côr dos dentes com a calcificação é frequente entre os autores de nomeada. ERAUSQUIN $^{10}$ diz que a «transparência do esmalte é maior nos dentes bem calcificados, predominando então, o tom «amarelado da dentina». Continua afirmando «que o esmalte pobremente calcificado é menos transparente e apresenta uma côr esbranquiçada própria». Dá como exemplo os dentes temporários. Diz ainda que a «discontinuidade do meio calcificado determina muitas modificações na marcha dos raios luminosos», procurando explicar, assim, a diminuição 
de transparência do esmalte e consequente alteração de côr nos dentes. SCHOUR $^{34}$ relaciona a côr dos dentes decíduos com a pigmentação das estrias de Retzius. APRILE e FIGƯN 1 relacionam-na com menos calcificação. DELLA SERRA ${ }^{6}$ chama a atenção para a uniformidade da côr de tôda a coroa dos temporários, diferente do que ocorre com os permanentes.

Alterações na coloração podem aparecer mais tarde por diversas razões, como por exemplo, o aparecimento, na polpa, do tecido calcificado, às vêzes difícil de ser identificado si tecido esclerosado, dentina secundária ou tecido ósseo, contendo lacunas e vasos sanguíneos ${ }^{27}$. Êsses processos de calcificação, entretanto, são muito mais frequentes em dentes permanentes de indivíduos idosos, mas podem ser encontrados até mesmo em germes dentários ${ }^{21}$

Quanto à forma -- Genèricamente, a forma dos dentes temporários corresponde a dos homólogos permanentes. Tal fato levou DIAMOND ${ }^{7}$ a afirmar que, «com poucas exceções, não é necessária a descrição detalhada dos dentes temporários ou de leite, porque são muito parecidos em sua forma aos permanentes correspondentes...». Entretanto, a «coroa dos primeiros molares superiores temporários lembra mais os prémolares do que qualquer molar permanente» $\mathrm{e}$ 《o primeiro molar inferior temporário tem uma coroa que não se assemelha a nenhum dente permanente».6,43

Várias outras diferenças podem ser anotadas. Vejamo-las resumidamente. a - A maior dimensão no sentido mesio-distal em comparação com a altura cervico-oclusal contrasta com as medidas dos dentes permanentes. Dá aos temporários formas especiais: em taça, para os dentes anteriores, e, os molares parecem achatados ou atarracados ${ }^{11}$.

b - As superfícies vestibular e lingual dos molares decíduos são mais planas que as dos dentes permanentes.

c - Um rodete cervical é bem pronunciado nos dentes decíduos, de modo especial por vestibular, particularmente no primeiro molar.

d - A área colusal é menor nos molares temporários, mesmo respeitando a proporcionalidade de tamanho. Tal fato é devido à convergência das superfícies vestibular e lingual, especialmene do primeiro molar temporário, fazendo com que o diâmetro vestíbulo-palatino s e ja acentuadamente menor no plano oclusal do que ao nível do colo do dente.

e - A acentuada constrição do colo, com o esmalte terminando bruscamente, é uma das características morfológicas marcantes dos dentes decíduos ${ }^{44}$.

f - Em relação às coroas, as raízes dos dentes de leite são mais finas e mais longas que as dos permanentes. Nos dentes temporários anteriores mostram-se com maior achatamento no sentido mesio-distal, às vêzes com canais bifurcados ${ }^{3}$. Nos molares elas apresentam uma divergência que se inicia muito mais perto do colo e se acentua cada vêz mais para o ápice, diferente do que ocorre com os permanentes. 
Para um estudo completo da morfologia dos dentes dcíduos, além de clássicas anatomias dentais 1,6,7,43,44, recomendamos a excelente monografia de JORGENSEN ${ }^{91}$.

\section{ASPECTO MICROSCóPICO}

Esmalte dentário - o esmalte dos dentes decíduos é menos espêsso que o dos correspondentes permanen. Sua espessura, muito mais uniforme, é, aproximadamente, a metade.

Os prismas do esmalte dos dentes temporários obedecem à mesma orientação geral dos prismas dos dentes permanentes, porém, no têrço cervical, têm percurso diverso: enquanto que nos permanentes têm orientação para cervical, nos temporários mantém a mesma inclinação das faces laterais e conservam a orientação para oclusal $30,34,40$. No bordo cervical dos dentes caducos, os prismas são relativamente mais longos que o dos permanentes na mesma situação, visto que, nos dentes temporários o esmalte termina bruscamente, e não em bordo afilado como nos dentes permanentes ${ }^{11}$.

O esmalte parece ser menos duro e menos resistentes que o dos permanentes, e, também, apresentar menor quantidade de sais minerais ${ }^{6}$. Dosagem de fluoretos no esmalte dos dentes de leite sugere que a mineralização do esmalte permanece a mesma entre 3 e 12 anos ${ }^{13}$.

Junção amelodentinária - Apresenta, marcadamente, um contôrno em forma de «S» com a parte côncava voltada para a porção oclusal e a parte convexa para a parte cervical ${ }^{34}$.

Dentina - A espessura da dentina que cobre a polpa dos dentes decíduos é bastante reduzida, aproximadamente a metade, em comparação com a dos permanentes. Sòmente na zona frente ao sulco intercuspídio (correspondendo a.o teto da câmara pulpar) é, proporcionalmente, maior ${ }^{11}$ face ao alongamento dos cornos pulpares, bastante acentuado dentes de leite. KURER 22 , ao chamar a atenção para a importância da preservação dos dentes das crianças, indica sua observação pessoal de que, sòmente $30 \%$ dos dentes de leite examinados, oferece espessura esmalte-dentina com segurança para a preparação de cavidades classe 2 para amálgama, sem considerável risco para a polpa. Completo trabalho de medição de espessura de dentina nos dentes temporários encontramos em ARNIN \& DOYLE ${ }^{2}$.

A direção dos canalículos dentinários é, de modo geral, semelhante a dos permanentes. Sòmente na região do colo dos dentes temporários região da junção entre esmalte e cemento - os canalículos são mais horizontais, com percurso quasi em ângulo reto com as linhas incrementais, sem mostrar as características curvaturas primárias visíveis nos dentes permanentes ${ }^{34}$. Assim sendo, os estímulos que incidem sôbre a dentina, nessa região, irão provocar reações pulpares mais cervicais que nos dentes permanentes submetidos à idêntica agressão, pois nêstes a ondulação e inclinação dos canalículos dentinários farão com que a resposta apareça mais apicalmente. 
As linhas de contôrno de Owen ou linhas incrementais são raras na porção da dentina formada antes do nascimento. Uma linha neonatal é bem caracterizada, e, a dentina posteriormente produzida poderá apresentar as linhas de Owen mais nítidas.

Os espaços interglobulares são ausentes ou pouco frequentes na dentina dos dentes temporários formada antes do nascimento ${ }^{14}$.

A dentina do assoalho da câmara pulpar parece ser mais permeável28. A mineralização da dentina parece aumentar dos 3 aos 7 anos, passando a decrescer após essa idade ${ }^{13}$ nos temporários.

Cemento - Também o cemento dos dentes de leite é bastante semelhante com o dos permanentes. Entretanto, a luz polarizada mostrou, como diferença, uma acentuada radiação das fibras de Sharpey no cemento celular dos dentes de leite $\mathrm{e}^{20}$. o emprêgo da microscopia eletrônica e da microrradiografia permitiu identificar que, no cemento acelular dos dentes temporários, não são identificáveis as linhas incrementais, e, em alguns casos, que é mais mineralizado que a dentina subjacente $\mathrm{e}^{12}$.

Polpa dental - A polpa dental é uma variedade de. tecido conjuntivo particular, extremamente frouxo, quasi embrionário. Seus componentes são, como os dos demais tecidos conjuntivos, células e substância intercelular. As células são principalmente, fibroblastos e histiócitos; porém, na polpa dental, existe uma variedade especial de células que só aí exis- tem, os odontoblastos. A substância intercelular é, em parte, do tipo fibroso e, em grande parte, do tipo amorfo, gelatinoso, que lhe dá uma consistência particular.

A polpa dental se origina do mesênquima; gradativamente, alguns de seus elementos vão assumindo diferenciação e participando da produção de dentina, enquanto outros permanecem bastante indiferenciados.

Isso acontece com a polpa dos dentes temporários, e, mais tarde, de modo semelhante, com a dos permanentes. Assim sendo, poucas são as diferenças que encontramos entre elas.

Se examinarmos com pequeno aumento um preparado histológico de polpa dental encontraremos, junto à prédentina, em tôda a periferia da polpa coronária e radicular, um conjunto de células, dispostas como se fossem um epitélio pseudoestratificado: são os odontoblastos. Imediatamente para dentro da camada odontoblástica aparecerá uma zona cuja característica principal é a pobreza em elementos celulares, denominada zona basal de Weil ou zona acelular. Mais interiormente, contrastando com a escassez celular da zona basal, ver-se-á uma faixa extremamente rica em células. É a zona celular ou celular subjacente. Essas três zonas correspondem à polpa periférica, por alguns denominada de zona funcional. Todo o restante da polpa dental é ocupado por estroma fibroso, substância amorfa, células, vasos e nervos.

Vejamos, separadamente, alguns elementos constituintes das diversas 
zonas. Polpa central - Quantitativamente, é a parte principal, composta de substância amorfa, dum estroma fibroso, de fibroblastos estrelados e anastomosados, de hịstiócitos, de algumas células imigrantes e dos mais calibrosos vasos e feixes nervosos.

Os vasos arteriais penetram pelo ou pelos condutos radiculares. Geralmente uma (ou duas) arteriolas em cada conduto correm pela parte central do mesmo, dando poucas ramificações durante o trajeto radicular e ramificando-se de forma abundante na polpa coronária. Se penetra uma só arteríola, ela tem curso central; quando duas, estendem-se próximo às paredes do conduto 41 para depois se ramificar. Estas ramificações, já com características capilares, atingem a zona celular e a camada odontoblástica. A rede capilar se resolve em vênulas, geralmente em maior número que as arteríolas, que voltam pelo centro do conduto.

Nos dentes temporários, que respeitam essa arquitetura geral, têm sido evidenciados vasos mais ou menos calibrosos atravessando a parede dentinária, em ambas as direções, relacionando o conduto redicular com a membrana periodontal ${ }^{33}$.

Provas funcionais indicam circulação linfática presente na polpa dental.

Os feixes nervosos volumosos penetram e ramificam-se em forma ou menos semelhante nos vasos. Junto à zona celular subjacente, resolvem-se em um plexo - o plexo de Raschkow - negado por uns, confirmado por outros ${ }^{23}$.
A partir dêsse plexo nervoso, fibras isoladas atravessam a zona basal e terminam entre ou sôbre os odontoblastos, podendo atingir a prédentina. Em nossa investigação pessoal23 sôbre o assunto não identificamos fibras nervosas além da prédentina. Também alguns trabalhos de microscopia eletrônica não têm revelado elementos nervosos além dessa camada. ${ }^{18}$.

RAPP e AVERY ${ }^{32}$, analisando a distribuição dos nervos nos temporários examinaram dentes com raiz em formação, com raiz completa e com raiz em reabsorção. Nos dois primeiros grupos não acharam diferencas com os permanentes, porém, nos dentes com raizes em reabsorção, evidenciaram que os feixes ou plexos parietais eram de difícil evidenciação, e que, naqueles dentes com grandes reabsorções, até mesmo os feixes centrais não apareciam.

o estroma fibroso é, essencialmente - e de modo especial nos dentes jovens - de fibras précalágenas. As fibras colágenas são mais escassas, porém podem tornar-se mais numerosas com a idade e em algumas reações pulpares. As fibras elásticas não aparecem ${ }^{17}$.

Os fibroblastos, bastante indiferenciados, têm potencialidade reacional bastante ampla. WEATHERFORD III 42 , citando Hill e Saltzer, lembra que a tendência da polpa a formar tecido calcificado «não está limitada à camada odontoblástica» e que «qualquer célula mesenquimática pulpar pode assumir a formação de tecido dentinóide», como sugerem as múltiplas calcificações. Já tem 
sido observada a diferenciação de fibroblastos pulpares em odontoblastos jovens, frente a diferentes estímu$105^{5}, 15,16,25,26,38$.

Os histiócitos - e sob esta denominação incluímos tôdas as células mesenquimáticas indiferenciadas e macrófagos - não são distintos dos que encontramos no restante dos tecidos conjuntivos 17,29 .

Pouco conhécemos das possíveis diferenças quanto ao aspecto histoquímico, entre polpas de dentes temporários e permanentes. Entretanto, pesquisa com relação a alguns com ponentes não revelaram variação $0^{32}$.

Zona basal e zona celular - Já indicamos suas características. Resta-nos apontar que, entre as células que integram a chamada zona celular subjacente, muitas, por sua morfologia e orientação, parecem estar em condições de substituir os odontoblastos, conforme nossa própria observação ${ }^{24}$.

Os odontoblastos - São as células próprias e específicas da polpa dental. Dispõem-se e distribuem-se como se fôssem um epitélio pseudo-estratificado, ao longo de tôda a superfície da polpa, embora tenha sido descrito o contato direto do sincício pulpar, por ausência dos odontoblastos, com a superfície dentinária radicular ${ }^{9}$.

Nos espaços deixados entre essas células, encontramos as fibras précolágenas de Von Korff, e SYMONS ${ }^{39}$ cita ainda haver encontrado as chamadas «células radiais».

Os odontoblastos, cujo corpo celular se localiza na polpa, apresentam um prolongamento apical - a fibrila de Tomes - que, alojada no canalículo dentinário, atinge a peri- feria da dentina, isto é, chega até as junções amelodentinária e cementodentinária.

Qualquer excitação exercida sôbre essas fibras - e elas são aos milhares por milímetro quadrado - provoca reação do elemento celular. Essas excitações ou agressões podem ser a cárie, o preparo cavitário, o contato com substâncias medicamentosas ou restauradoras, a abrasão, etc. A reação, que varia conforme a agressão e a capacidade vital da polpa, pode ser a produção de dentina secundária ou reparadora, a inflamação, as degenerações, a necrose.

Consideramos, concordando com a quase totalidade dos autores consultados, o odontoblasto como uma célula perene; alguns 8,41 usam exatamente essa expressão: perene. Surpreende-nos a informação de MOSS ${ }^{28}$, citando Schour, que as células formadoras de dentina sejam «funcionalmente ativas por, aproximadamente 350 dias nos dentes temporários e por 700 dias nos dentes permanentes». Aliás, BEVELANDER ${ }^{4}$, em trabalho com microscopia eletrônica, chama a atenção para a «habilidade potencial destas células para desenvolver ativo metabolismo».

Embora não haja unanimidade do ponto de vista quanto ao modo de participação, parece aos investigadores que o odontoblasto colabora na formação da matriz orgânica da dentina. Voltamos a chamar a atenção para a potencialidade de células centrais produzirem tecido calcificado por diferenciação de fibroblastos ${ }^{42}$.

Quanto à possibilidade de reação da polpa dental está condicionada a vários fatôres ${ }^{35}$. Ela se manifesta, 
particularmente, pelo aparecimento de dentina de reparação ou dentina secundária. Entretanto, êsse processo de defesa «parece ser uma resposta pessoal e variável à injúria» 37 . Recomendamos, aos que pretendem investigar sôbre as reações pulpares, a observação das etapas no preparo do material e na análise e avaliação dos resultadas, etapas preconizadas por STANLEY ${ }^{36}$, a fim de permitir uma correta comparação com os trabalhos dos diferentes investigadores.

Para concluir, queremos registrar que, no manuseio de dentes temporários e permanentes para realização de preparações por desgaste, os primeiros revelaram-se muito mais friáveis, quebranđo-se fàcilmente segundo planos de clivagem, dificultando a obtenção do material.

\section{RESUMO}

Particularidades consideradas importantes para melhores preparo cavitário e comportamento terapêutico nos dentes decíduos foram estudadas numa análise histológica comparativa com os permanentes, baseada no exame de preparações obtidas por desgaste e por descalcificação.

\section{SYNOPSIS}

Particularities considered important for better cavity preparation and therapeutic behaviour in deciduous teeth were studied in a histologic analysis compared to permanent teeth, based on the examination of decalcified and ground sestions.

\section{REFERÊNCIAS BIBLIOGRÁFICAS}

1. APRILE, H. \& FIGÚN, M. D. Anatomia odontológica. 3.ed. Buenos Aires, El Ateneo. 1960. p. 363.

2. ARNIN, S. S. \& DOYLE, M. P. Dentin dimensions of primary teeth. J. Dent. Child. 1959. p. 191.

3. BENFATTI, S. V. \& ANDRIONI, J. N. Morfologia dos dentes decíduos anteriores pelo processo de diafanização. Arq Cent. Est. Fac. Odont. UFMG, 5:1, 123, jan.-jun., 1968.

4. BEVELANDER, G. \& NAKAHARA, H. An E. M. study of human odontoblast. IADR, 1967, abstr. p. 102.

5. COTTON, W. R. Demonstration of odontoblast precursor cell by tritiates trymidine. J. D. Res., 43:810, suppl. set.-out., 1964. abstr.

6. DELLA SERRA, O. Anatomia dental. Rio de Janeiro, Científica, 1959. p. $246-48$.

7. DIAMOND, M. Anatomia Dental. 3.ed. México, Hispano-Americana, 1962. p. 62 .

8. ERAUSQUIN, J'. Contribución al estudio del odontoblasto. Rev. Odont., 26:289. jul., 1938.

R. Fac. Odont. P. A. 10/11: 105-113, 1968/1969 
9. ERAUSQUIN, J. Algunas observaciones sôbre la origen y la evolución de las fibras de Von Korff. Arch. Hist. Normal y Patológica, 3:493, set., 1947.

10. ERAUSQUIN, J. Histologia y embriologia dentária. Buenos Ayres, Progenthal, 1958. p. 21.

11. FINN, S. B. Clinical periodontics. 2.ed. Philiadelphia, Saunders, 1957. p. 59-60.

12. FURSETH, R. A microradiographic and electron microscopic study of cementum of human teeth. Acta Odont. Scand., 25:6, 613, dez., 1967.

13. HARGREAVES, J. A. \& WEATHERELL, J. A. Fluoride content of dentin and enamel in human deciduous teeth. J. D. Res., 43:810. suppl. set.-out., 1964. abstr.

14. ISOKAVA, S. et alii. Interglobular dentin in deciduous teeth. J. D. Res., 32 :831, mai.-jun., 1963.

15. JAMES, V. E. \& WEIMANN, J. P. Response of human pulp to paraformaldehyde and cavity preparation. J. D. Res., 33:663. out., 1954. Abstr.

16. JAMES, V. E. et alii. Biology of the pulp and its defense. JADA, 59:903, nov., 1953.

17. JAMES, V. E. Response of the pulp of dog, monkey and man to baseplate gutta-percha and cavity preparation. J. D. Res., 32:656, out., 1953. Abstr.

18. JESSEN, H. Ultrastructure of odontoblast. Acta Odont. Scand, 25 (5) : 491, dez., 1967.

19. Jorgensen, K. D. The deciduous dentition. Acta Odont. Scand., 14: supl. 20, 1956.

20. KELLER, H. Polarisationoptische untersuchung der faserstruktur in zement entkalkter menschlicher milkzähne. Acta Ant., 57:326, 1964.

21. KRONFELD, R. Histopatologia dos dentes. 3.ed. Rio de Janeiro, Científica, 1955.

22. KURER, J. Deciduous molars cavity preparation. Brit. D. J., 101:244, 1956.

13. LOURO, L. M. Inervação da polpa dentária e da dentina. Pôrto Alegre, 1958 (tese).

24. LoURO, I. M. Odontoblasto; estudo comparativo. Rev. Fac. Odont. P. A., 2 :65, jan--dez., 1960 .

25. MARUSHIMA, M. Dentinogenic response of the tooth pulp to calcium hydroxide application. J. D. Res., 36:653, out., 1957, abstr.

26. MELLo, C. F. Polpa dentária; alguns aspectos de sua histifisiologia. Rio de Janeiro, 1939 (tese).

27. MORRIS, M. E. Pulpal changes in traumatized primary central incisors. IADR, 1966. p. 135, abstr. 
28. MOSS, S. J. et alii. Histologic study of pulpal floor of deciduous molars. JADA 70:372, fev., 1965 .

29. ORBAN, B. Contribution to the histology of dental pulp and periodontal membrane with special reference to the cells of defense of these tisues. JADA, 16:965, jun., 1929.

30. ORBAN, B. Óral histology and embriology. 4.ed. St. Louis, Mosby, 1957. p. 63 .

31. RAPP, R. \& AVERY, J. K. A study of nerves in human primary teeth. IADR, 41:41, 1963, abstr.

32. RAPP, R. \& STRACHMAN, O. S. Multiple esterases in human dental pulp of permanent and primary teeth. IADR, 134, 1966, abstr.

33. RUSSEL, L. H. \& KRAMER, R. H. Observation on the vascular architeture of dental pulp. J. D. Res., 35:957, dez., 1956, abstr.

34. SCHOUR, I. Noyes oral histology and embriology. 8.ed. Philadelphia, lea \& Feabiger, 1960, p. 300-3.

35. STANLEY, H. R. Design for a human pulp study. Part. I Oral Surg., Oral Med., and Oral Path., 25:633, apr., 1968 e Part II, 25:756, mai., 1968.

36. STANLEY, H. R. The factors of age and tooth size in human pulp reactions. Oral Surg., Oral Med., and Oral Path., 14:4, 498, apr., 1961.

37. STONER, J. E. Dental caries in deciduous molars. Brit. D. J., 123: 132, agô., 1967.

38. SVEEN, O. B. \& HAWES, R. R. The differentiation of odontoblasts after injury to dental pulp. IADR, 134, 1966, abstr.

39. SYMONS, N. B. B. The cells of the odontoblasts, ameloblasts and internal enamel epithelial layers. J. D. Res., 33:779, out., 1955, abstr.

40. TURELL, J. C. La estructura histológica del esmalte y su relación con preparación cavitarias. Anales Fac. Odont., Montevideo, n. 2, vol. II, tomo II, $2^{\circ}$ sem., 1955, p. 159-180.

41. VULCANO, H. Vascularização e inervação da polpa dentária. Rio de Janeiro (tese).

42. WEATHERFORD III, T, W. Alguns aspectos histológicos, fisiológicos y farmacológicos de la terapia pulpar en paidondoncis. Bol. Inf. Dental, 25:199, mai., 1965.

43. WHEELER, R. C. A textbook of dental anatomy and phisiology. 4.ed. Philadelphia, Saunders, 1965. p. 49.

44. ZEISZ, R. C. \& NUCKOLLS, J. Dental anatomy. St. Louis, Mosby, 1949. p. 351.

R. Fac. Odont. P. A. 